жруппы при нормальных цифрах общего количества лейкоцитов. Некоторая тенденция к повышению количества тромбоцитов.

VIII группа - обнаружен только умеренный сдвиг нейтрофильной группы влево.

Результаты исследования белой крови могут быть сформулированы в следующих положениях:

1. Имеются изменения как общего количества лейкоцитов, так и отдельных составных элементов лейкоцитарной формулы.

2. Изменения эти заключаются в том, что при прогрессировании ракового процессса увеличивается: а) общее количество лейкоцитов; б) сдвиг влево за счет нейтрофильной группы; в) формы раздражения; г) количество моноцитов.

3. Количество эозинофилов стоит в некоторой зависимости от осложняющих рак кровотечений.

4. Относительный лимфоцитоз нами установлен у больных после расширенной экстирпации раковопораженной матки.

5. Количество базофилов оказалось нормальным во всех группах.

Тромбоциты подлежат специальному рассмотрению. Они были: а) повышены у больных с рецидивами рака шейки матки; б) понижены во II стадии рака (без кровотечений) и среди группы больных, подлежавших профилактическому радиооблучению после экстирпации матки.

Итак, сопоставление приведенных данных по отдельным группам ражовых больных показывает, что изменения со стороны красной и белой крови по этим группам не одинаковы. При этом в каждой стадии болезни мы смогли отметить ряд гематологических черт, связанных как с основным заболеванием, так и с сопровождающими его осложнениями.

Поступила 12 января $1960 \mathrm{r}$.

\title{
ТКАНЕВАЯ ТЕРАПИЯ АМЕНОРРЕИ
}

\section{Засл. врач РСФСР В. И. Нванова}

Из клиники акушерства и гинекологии (зав.-проф. Н. Е. Сидоров) Казанскөго ГИДУВа им. В. И. Ленина

Тканевая терапия, разработанная и введенная в медицинскую практику академиком В. П. Филатовым, получила широкое распространение в Советском Союзе и привлекла всеобщее внимание.

Әто побудило и нас использовать метод тканевой терапии в лечении аменорреи, как первичной, так и вторичной. Для подсадки мы применяли раньше яичник и селезенку теленка, а в дальнейшем стали использовать плаценту родильниц. Ткани приготовлялись по временной инструкции Министерства здравоохранения CCСP от 27/VII-50 г.

Подсадка ткани производилась в области .тевого подреберья по передней аксиллярной линии. После обработки операционного поля спиртом и настойкой йода следовала анестезия кожи $0,25 \%$ раствором новоканна в количестве $20-25$ мл по линии будущего разреза длиной 2-3 см. Дальше игла проходила до апоневроза, чтобы анестезировать будущий карман для ткани. В области анестезированного участка делался разрез кожи, тупо раздвигалась жировая клетчатка до апоневроза, формировался карман, куда и укладывалась консервированная ткань, которая погружалась как можно глубже во избежание секвестрации. Қарман жировой клетчатки должен быть сухим. Подсаживалось 3 г ткани. На кожу раны накладывали $2-3$ шелковых шва и асептическую наклейку.

Критериями для оценки результатов лечения служили: появление месячных, субъективное состояние больной (хороший сон, аппетит, повышение жизненного тонуса).

Всего под нашим наблюдением было 82 больных, из них с первичной аменорреей -18 и с вторичной -64 . 
С первичной аменорреей были в возрасте от 22 до 30 лет -17 , 34 лет - 1. Девственниц было 6 и замужних 12.

У 7 причиной аменорреи была недостаточность яичников. С невыясненной этиологией было 10 , и одна больная связывала отсутствие менструаций с перенесенной операцией по поводу кисты.

При исследовании мазков влагалища у 5 больных недостаточность функции яичника соответствовала реакции 2 типа. У 11 больных произведена рентгенография турецкого седла; во всех случаях изменений не обнаружено. У 12 больных реакция Ашгейма - Цондека во всех случаях оказалась отрицательной. 9 больным прозводили соскоб слизистой стенок полости матки. Әлементов слизистой ткани в них не обнаружено.

До подсадки 18 больным безуспешно применялась гормонотерапия. Кроме гормонотерапии, 3 больным назначалось укрепляющее лечение. После неудачного лечения гормонами были направлены в клинику для тканевой терапии через 4 месяца 5 больных, через 6 месяцев -6 и через 8 месяцев - 7 .

Подавляющее большинство жаловалось на постоянные головные боли, бессонницу, резкую раздражительность, быструю утомляемость, отсутствие аппетита, менструаций. Ввиду такого состояния две больные даже прекратили работу. Четырем больным произведена подсадка яичника двухлетней телки, шести - подсажена телячья селезенка и восьми - плацента. Яичник подсажен 3 больным по 2 раза и одной больной 1 раз. Селезенка подсажена 2 больным по одному разу, 2 - по 2 раза и 2 по три раза. Плацентарная ткань подсаживалась 6 больнєм 2 раза и двум по одному разу. Интервалы между подсадками были 2 месяца.

После первой подсадки общее состояние больных резко улучшилось, появлялись аппетит, спокойный сон, исчезала головная боль. Менструации пришли у 9 больных (у 2 после первой подсадки через 3 недели и стали приходить регулярно через 21 день; у 5 менструации пришли после второй подсадки и у 2 после 3 -й). Среди этих больных было с недостаточностью функции яичников 7 женщин и с невыясненной этиологией 2, у остальных 9 крови не пришли, но общее состояние улучшилось. Срок наблюдения - от 3 до 4 лет.

С вторичной аменорреей мы лечили 64 больных. В возрасте до 25 лет было 10 , от 26 до 30 лет - 13, от 31 до $35-25$, от 36 до $39-16$ чел. Замужних было 56 (у 35 имеются дети), вдов - 4, девиц - 4. Давность заболевания - от 6 месяцев до 6 лет.

Аменоррея возникла после психической травмы у 11 , после выскабливания стенок полости матки при неполном выкидыше-у 8; после искусственного аборта - у 3; после выскабливания по поводу приращения последа - у 7 и после удаления кисты яичника - у 3. С невыясненной этиологией было 32.

Для выяснения состояния слизистой оболочки тела матки 32 больным прозводилось диагностическое выскабливание, при этом только у одной обнаружена железистая гиперплазия. У остальных элементов слизистой оболочки в соскобах не обнаружено.

Рентгенография черепа (турецкого седла) произведена 50 больным, у 49 турещкое седло было в пределах нормы. У одной вход выше полости в турецкое седло расширен, но акромегалии клинически не обнаружено.

У всех 64 реакции с мочой на сперматоурию и Ашгейма - Цондека были отрицательными. Цитологическое исследование содержимого влагалища произведено 24 больным. У 6 была IV типа реакция, у 14-III-го и у 4 -II-го.

До подсадки консервированной ткани больным безуспешно применялась гормонотерапия.

Все поступили в клинику с жалобами на головную боль, раздражи- 
тельность, плохие сон и аппетит, отсутствие менструаций, интереса к жизни.

Данной группе больных сделано 110 подсадок консервированной ткани. По одной -30 больным, по $2-22$ и по $3-12$. Плацента подсаживалась 40 больным, селезенка - 10, селезенка и яичник (букет) - 14 . Подсадки повторялись с интервалом в 2 месяца.

После лечения менструации пришли у 27 больных: у 17 после подсадки плаценты, у 6 - после подсадки селезенки и у 4 -после подсадки селезенки и яичника. После первой подсадки крови пришли у 11 , после двух подсадок у 6 , после $3-$ у 10 .

Среди этих больных с невыясненной этиологией - 18, после выскабливания полости матки по поводу приращения последа - 2, после выскабливания по поводу неполного выкидыша - 2, после психической травмы - 4, после удаления кисты яичника - 1 больная. У 37 после трех подсадок менструации не пришли, но общее состояние резко улучшилось: исчезли головные боли, появился аппетит, поднялся жизненный тонус, появились желания. Длительность наблюдения $-4-5$ лет.

Из 27 выздоровевших у одной наступила беременность, но, к сожалению, внематочная.

\title{
ВЫвОдЫ:
}

1. Тканевая терапия эффективна при лечении первичной и вторичной аменорреи.

2. Специфичности действия применяемых для подсадки консервированных тканей нами не обнаружено.

\section{ЛИТЕРАTУРА}

1. П а вленко С. М. Сов. мед., 1953, 8. - 2. Фил а тов В. П. Тканевая терапия, 1948.- 3. О н же. Хирургия, 1949, 8.-4. О н же. Клин. мед., 1950, 1.

Поступила 18 мая 1959 г.

\section{РЕАКЦИЯ СПЕРМАТОУРИИ САМЦОВ ОЗЕРНОИ ЛЯГУШКИ ПРИ РАСПОЗНАВАНИИ ХОРИОНЭПИТЕЛИОМЫ}

\author{
Асс. М. А. Давыдова
}

Из клиники акушерства и гинекологии (зав. - проф. Н. Е. Сидоров) Қазанского ГИдуВа им. В. И. Ленина

Распознавание хорионэпителиомы в ряде случаев бывает затруднительным ввиду того, что клиника этой болезни не является специфичной. Поэтому любой метод, способствующий уточнению диагноза хорионэпителиомы, несомненно, имеет практическое значение.

Решающим для окончательного диагноза считается гистологическое исследование.

В дополнение к нему используются и гормональные реакции, в частности, реакция Ашгейма - Цондека. При хорионэпителиоме, как правило, хориальный гонадотропин продуцируется значительно больше, чем при нормальной беременности. Поэтому реакция бывает положительной при разведении мочи больной в 100, 200 и более раз.

Были сделаны отдельные попытки применить реакцию сперматоурии для диагностики хорионэпителиомы (А. А. Давиденко, М. Х. Бабаян, И. С. Эйбер, Е. Е. Самойлова).

Мы использовали реакцию сперматоурии самцов озерной лягушки при подозрении на хорионэпителиому матки с мочой 23 больных ${ }^{1}$. Из них

1 Техника реакции сперматоурии, применяемая нами, описана в Трудах Казанского ГИДУВа им. В. И. Ленина, 1958, т. XIII, стр. $96-103$. 